\title{
Research on SMEs' Financing Against the Background of Internet Finance - Based on Block Chain Technology
}

\author{
Yuyan Zhou ${ }^{1}$, Yana Zhou, \\ ${ }^{1}$ Sichuan University, Jincheng College, Chengdu, Sichuan, China \\ ${ }^{2}$ Yunnan University of Finance and Economics, Kunming, Yunnan, China \\ *Corresponding author. Email: 114202778@qq.com
}

\begin{abstract}
As an important part of China's national economy, small and medium-sized enterprises (SMEs) play an important role in promoting China's economic growth, expanding jobs and increasing national tax revenue. However, due to the small scale of SMEs, low level of credit, lack of collateral, they are often plagued by narrow financing channels, financing difficulties and expensive financing, so a new technology is urgently needed to solve the current financing plight of SMEs. In recent years, block chain technology has attracted wide attention worldwide due to its decentralized and trustfree technical mechanism, and has become another new thing that can be popularized and applied on a global scale after the Internet. In this paper, "block chain" and "finance" are perfectly combined, aiming to use the properties of decentralization, immutability and traceability of block chain technology to improve the credit level of small and medium-sized enterprises and expand their financing channels. It is expected to effectively solve the financing difficulties of small and medium-sized enterprises, promote the sustainable and healthy development of small and medium-sized enterprises, and make greater contributions to the national economic growth.
\end{abstract}

Keywords: Block chain, SMEs, Finance, Financing.

\section{INTRODUCTION}

With the continuous development of reform and opening up, small and medium-sized enterprises have gradually become the backbone of China's market economy, making important contributions to the country's technological innovation and the increase of GDP, and solving more than $80 \%$ of urban employment problems. However, due to their small size, single financing channels and low credit, it is difficult for small and medium-sized enterprises to circulate necessary funds in the traditional financial market, which seriously hinders their further development. Therefore the emergence of new technologies is in urgent need to solve the financing problems of SMEs.

\section{FINANCING PLIGHT OF SMALL AND MEDIUM-SIZED ENTERPRISES}

\subsection{Single Financing Channel for Small and Medium-sized Enterprises}

Financing channels can be divided into internal financing and external financing. Internal financing refers to the use of their own capital, capital base and undistributed profit to raise funds. External financing refers to the process in which an enterprise absorbs the savings of other economic entities and converts them into its own investment, mainly including bank loans, equity financing, lease financing, commercial credit, development bank loans and other sources. China's small and medium-sized enterprises often can only obtain funds through internal financing because of the small scale, especially in the early stage of 
entrepreneurship. The scale of internal financing is small, and it is difficult to meet the capital needs of enterprises. Among external financing channels, SMEs often only rely on bank loans, and due to the small size of SMEs and low credit rating, bank loan funds also have certain limitations. The single financing channel is not conducive to the development of small and medium-sized enterprises, but also makes the financing risk of small and medium-sized enterprises too concentrated.

\subsection{Small and Medium-sized Enterprises Have Low Credit Level and Lack Collateral}

Credit is the basis of economic activities, and the financing needs to be guaranteed by the credit of both sides. The financing difficulty of SMEs doesn't come from lack of market funds or a sound capital market, but mainly from the low credit of SMEs themselves. In China, the credibility of small and medium-sized enterprises is not high, and the ability to defend risks is weak. When they encounter debt risks, they are prone to the phenomenon of debt dragging and debt evasion, which leads to the low credit rating of small and medium-sized enterprises. Commercial banks are profit-making institutions. Because of their special characteristics of debt operation, they put the security of funds in the first place, so they have higher requirements on the credit rating of loan objects. At the same time, in order to avoid risks, banks and other financial institutions require loan enterprises to provide collateral with a certain market value. Yet since small and medium-sized enterprises are mainly technology service enterprises and their fixed assets are less and the value is low, it is difficult for them to meet the requirements of banks and other financial institutions for collateral.

\subsection{SMEs Have Higher Financing Costs}

Information asymmetry refers to the deviation and imbalance of information distribution between different economic subjects. Due to market failure, information asymmetry between capital supply and demand leads to relatively high financing costs of SMEs. First of all, small and medium-sized enterprises themselves have low level of information disclosure, coupled with the collateral of the inferior compared with large enterprises; therefore, in order to reduce their own risks and ensure the safety of funds, banks need to conduct more rigorous and complex credit audit on SMEs before lending. At the same time, in order to prevent adverse selection and moral hazard, banks charge higher loan interest to SMEs, which increases the financing cost of SMEs. Secondly, due to information asymmetry, banks and other financial institutions tend to lower the risk assessment value of SMEs, especially emerging technology enterprises, which also increases their financing costs. Finally, the financing of SMEs has the characteristics of short term, small amount of, high frequency and strong timeliness. This requires financial institutions to grant credit for many times, which increases their workload, and thus increases the loan cost.

\section{CHARACTERISTICS OF BLOCK CHAIN}

The concept of Block Chain was first proposed by Satoshi Nakamoto in his paper "Bitcoin: A Peerto-Peer Electronic Cash System" in 2008. Block chain refers to a string of cryptographically linked blocks of data, each of them containing information about all Bitcoin transactions in the past ten minutes, to verify the validity and authenticity of their information and generate the next block. Applying the characteristics of decentralization, immutability and traceability of block chain technology to enterprise financing will effectively alleviate the financing difficulties of SMEs.

\subsection{Decentralization}

Block chain uses distributed ledger technology, which does not require a central server to link individual nodes. Each node in the block chain records data separately, and it keeps a true and complete transaction record. Each node directly exchange data and information, trust each other, and no longer needs to pass information through the central server, which greatly saves the cost, makes the sharing scope larger and the time needed shorter. And there won't be such phenomenon of central server damage and the whole network to stop running.

\subsection{Immutability}

The data stored in each block of the block chain is encrypted using the principle of asymmetric cryptography, that is, the cryptography of the block chain is completed by a pair of asymmetric secret keys. Data is encrypted with the public key and decrypted with the private key. Some of the information is available to the public, but the full 
information can only be seen by the parties who have the key. Moreover, the data on each node will not be tampered with after entering the block chain through the whole network verification. Unless more than $51 \%$ of the nodes in the whole system can be modified at the same time, it is invalid to modify the information of a single node. Therefore, the information in the block chain has high security and cannot be tampered with.

\subsection{Traceability}

Data stored on the block chain is both secure, not to be tampered with, and traceable. Traceability is achieved using a timestamp technique. When new data are generated, they will be published to the whole network, and a new block will be formed after each node of the whole network verifies it one by one. At the same time, the system uses the timestamp technology to automatically time stamp the new block. In this way, each block in the system has its own time mark, which helps people to identify the sequence of data formation and adds a time dimension to data information. Thus the authenticity and traceability of the data within the block chain system can be ensured.

\subsection{Smart Contract}

The contract compiled by using block chain technology is an automatic contract system, which refers to a programmable network protocol automatically judged and executed by the system according to preset rules and data cannot be tampered with. In the specific application, only the rules of the project need to be formulated into smart contract code. Block chain can record the code and project status in the block and the block chain executes the project code. As long as the information conforms to the terms of the contract, the contract will be automatically executed intelligently. In addition to the function of automatic recognition and execution of contracts, smart contracts of block chain can also guarantee the authenticity and reliability of project data through the traceability and immutability of block chain. The smart contract of block chain is suitable for a large number of repetitive operations of the project, and can save a lot of manpower and material resources, save costs; at the meantime the automation can also avoid the risk of manual operation.

\section{APPLICATION OF BLOCK CHAIN TECHNOLOGY IN SME FINANCING}

\subsection{The Decentralized Mechanism of Block Chain Can Broaden the Financing Channels of SMEs}

Block chain is a decentralized distributed accounting method. There is no single central database, and any transactions that occur will be published to the whole network and confirmed by individual nodes before new blocks are formed. As for the attempt of tampering with information, a malicious attack on a single node will not affect the information of other nodes, and to modify a single piece of information one must control more than $50 \%$ of the nodes to achieve the purpose. The financial institutions and enterprises in the system can realize the public transparency of information. The transaction information of enterprises is stored in the block chain and will not be tampered with, which ensures the credit of small and medium-sized enterprises, reduces the cost of investment risk assessment of enterprises by financial institutions, enhances the willingness to invest in small and medium-sized enterprises, and thus broadens the financing channels of small and medium-sized enterprises. In addition, small and medium-sized enterprises can use block chain technology to raise funds privately.

\subsection{The Immutability and Traceability of Block Chain Can Improve the Credit Level of Small and Medium-sized Enterprises}

The reason why SMEs are difficult to finance lies in the serious information asymmetry between commercial banks and other financial institutions and enterprises. First, it is difficult for financial institutions to judge the authenticity of the information provided by enterprises in financing. Second, the initiative of financial institutions in the lending market is not good, and because the search cost is too high, banks are often in a passive position. The distributed storage feature of block chain makes all data and information public in the whole system, and the data is timestamped. Once confirmed, the data is no longer reversible and will not be tampered with. In other words, the information faced by financial institutions in the system can be guaranteed to be true and reliable. In addition, for each transaction, the node must 
publish the information to the whole network, so that financial institutions can view the information of the enterprise at any time and trace the source of the information, which saves a lot of time and labor costs for financial institutions. The irreversibility and traceability of the data stored in the block chain improve the credit level of SMEs, eliminate the information asymmetry between financial institutions and enterprises, and improve the financing efficiency of the financial market.

\subsection{The Smart Contract of Block Chain Can Reduce Financing Costs for SMEs}

Due to their small scale, limited business volume, the demand of small and medium-sized enterprises for capital is generally small in amount, yet with high frequency. If every loan of funds is approved in accordance with the conventional procedures, it will consume a lot of manpower and material resources of financial institutions, which will lead to the increase of their financing costs for SMEs. The smart contract of block chain system can effectively reduce the financing cost of small and medium-sized enterprises. The Block chain system encodes the verification conditions into the smart contract in advance. When small and medium-sized enterprises make loan requests, the smart contract will automatically carry out the loan verification procedure. In addition, the traceability of the block chain can be used to trace the authenticity of the collateral, which not only reduces the cost but also avoids the mistakes that may occur in manual operation. In addition to the audit in advance, the loan management of commercial banks also needs the supervision and management of receivables after the event, which also requires a large human cost. The smart contract of the block chain can automatically complete the supervision and management work, and the data in the block chain cannot be tampered with, which can ensure the fairness and fairness of the supervision work, thus improving the financing efficiency of SMEs and reducing the financing cost.

\section{CONCLUSION}

The number of small and medium-sized enterprises in China is large, accounting for more than $80 \%$ of the total number of enterprises in the country, which play an immeasurable role in the development of China's economy. Information asymmetry is the core problem of financing difficulty for small and medium-sized enterprises.
The distributed accounting method of block chain technology and its tampering-proof characteristics ensure the authenticity of SMEs' data, improve their credit rating and broaden their financing channels. Block chain's smart contract function and traceability reduce the search cost and financing cost of financial institutions, and provide a guarantee for the precise connection between the supply and demand of funds. Of course, it is also necessary to see that since the block chain technology is still in continuous iterative evolution, there are still some risks, and a lot of unsolved technical problems and difficulties. This requires strengthened efforts in the research on block chain technology, regulatory authorities' formulation of corresponding management policies, to improve the corresponding mechanisms and provide a safer and more efficient financing environment for small and medium-sized enterprises, so as to promote the further development of China's economy.

\section{AUTHORS' CONTRIBUTIONS}

Yuyan Zhou contributed to designing and writing this paper. Yana Zhou is responsible for revising this paper.

\section{REFERENCES}

[1] Xian Jingchen. The Development and Prospect of "Block chain + Internet Finance" [J]. Finance and Accounting Monthly, 2017(14): 79-83. (in Chinese)

[2] Jin Wei. Application Scenes of Block chain in the Field of Culture and Finance $[\mathrm{N}]$. China Times, 2016(07). (in Chinese)

[3] Zhang Xiaomei, Liang Hong, Jiang Haoran. Block chain Financial Model and Credit Rationing of Small and Micro Enterprises [J]. Shanghai Finance, 2016(07): 35-40. (in Chinese)

[4] Gong Xiaolin, Yang Wang, Qu Shuangshi. The Technical Principle of Block Chain and Its Application in the Financial Field. International Finance, 2017(02): 46-54. (in Chinese)

[5] Hu Hongwei. Analysis on Financing Problems of SMEs Under the New Normal Economy. Hebei Enterprise [J]. 2021(01): 37-38. (in Chinese)

[6] Zhou Dayong, Wu Yao. Supply Chain Finance and Technology-based Small and Medium- 
sized Enterprise Financing Under Block Chain Technology. New finance [J]. 2020(10): 49-54. (in Chinese)

[7] Xie Jiwei. Construction and Application of Accounting Model for Expense Reimbursement Based on Block chain Technology [J]. Communication of Finance And Accounting 2021(03): 143-147. (in Chinese)

[8] Zhao Chunya, Zhou Lei. Review and Prospect of Research on Block chain Financial Model Serving Small and Micro Enterprises Financing. Jiangsu Commercial Forum [J]. 2020(12): 88-92. (in Chinese)

[9] Li Xiaochuan. Analysis on Financing Problems of Small and Medium-sized Enterprises Under Internet Finance Mode. Time Finance [J]. 2017(04): 143, 151. (in Chinese)

[10] Sun Hao, Zhou Zhiyi, Fu Taosha. Research on the Financing of Small and Mediumsized Enterprises Under the Background of "Block chain + Supply Chain Finance". Modern Business [J]. 2020(12): 48-50. (in Chinese) 